\title{
EFEKTIVITAS PELATIHAN EVALUASI MODEL BRINKERHOFF TERHADAP KEMAMPUAN MANAJER KEPERAWATAN MENGEVALUASI PELAKSANAAN STANDAR OPERASIONAL PROSEDUR TINDAKAN KEPERAWATAN DI RSI IBNU SINA PEKANBARU TAHUN 2013
}

\author{
Siagian, S.H ${ }^{1}$, Delvira, $\mathbf{W}^{2}$ \\ sitihotna@gmail.com
}

\begin{abstract}
When the act of nursing is not conducted properly in accordance with SOP, it will lead to the occurance of error and unexpected event during the nursing action process. Out of 12 nursing managers in RSI Ibnu Sina Pekanbaru, $90 \%$ of them stated have not been able to evaluate nursing action SOP. One of nursing manager abilities is able to assess, evaluate in regular basis whether his/her staffs have been working in accordance with appropriate action SOP. This ability can be improved through training given. This study aims to determine the effectiveness of Brinkerhoff evaluation training on nursing manager ability. This research was conducted in RSI Ibnu Sina Pekanbaru in March until June 2013. The research method used was Quasi-experimental with pre-post test design. Samples were gathered in total, i.e. 35 people. The instrument of data gathering were questionnaires. From Wilcxon test, it is found that there is significant difference before and after training with $p$ Value $=0,000 \alpha<0,05$. Therefore, it is suggested there must be SOP on evaluation of nursing action. A nursing manager is expected to conduct leadership role well ranging from planning, organizing, staffing, directing, and controlling by making Human Resource Development program through training, seminar and conduct monitoring and evaluation of the result of activities that have been done.
\end{abstract}

Key words: Training, Brinkerhoff model evaluation, Nursing manager ability References: 90 (1980-2013)

\section{PENDAHULUAN}

Keperawatan merupakan profesi yang berfokus membantu pasien mencapai secara optimal dengan cara memberikan pelayanan yang bermutu dan berkualitas. Pemimpin dan manejer perawat yang efektif adalah yang mampu memberikan pengaruh dan motivasi, mampu membuat keputusan bagi anggotanya.
Metode dan model evaluasi yang dipilih untuk pengembangan dalam penelitian ini dipilih sesuai dengan situasi dan kondisi yang mendukung strategi atau pedoman kerja manejer keperawatan dalam melakukan tugas kontroling dan evaluasi yaitu model yang dikemukakan oleh Brinkerhoff dalam Mardapi (2000). Alasan kuat menggunakan model evaluasi Brinkerhoff ini memungkinkan untuk 
dilakukan dalam pelayanan keperawatan yang memiliki elemenelemen yang similer pada pelayanan keperawatan yaitu : 1) menentukan focus dan desain yang akan dievaluasi, 2) mengumpulkan dan menganalisis informasi, 3) mengelola dan melaporkan hasil evaluasi.

\section{Tujuan Penelitian}

Untuk menganalisis efektivitas pelatihan terhadap kemampuan manejer keerawatan menegevaluasi Standar Operasional Prosedur tindakan keperawatan di RSI Ibnu Sina Pekanbaru.

\section{Jenis penelitian}

Penelitian ini menggunakan metoda riset kuantitatif dengan desain quasi eksperiment one group design

\section{Populasi dan sampel}

Populasi dan sampel dalam penelitian ini adalah seluruh manajer di RSI Ibnu Sina Pekanbaru yang berjumlah 35 orang.

\section{Tempat dan Waktu penelitian}

Tempat penelitian dilakukan RSI Ibnu sina Pekanbaru dimulai dari bulan Maret sampai dengan Juni 2013.

\section{Alat penggumpulan data}

1) Data karakteristik, meliputi: umur, jenis kelamin,lama kerja, diukur dengan kuesioner. 2) Data kemampuan, variabel pengetahuan, sikap diukur menggunakan kuesioner dan lembar observasi.

\section{Uji validitas dan reliabilitas}

Uji validitas dengan uji korelasi Pearson Product Moment. Hasil pengolahan SPSS dari 25 item soal, semua soal dinyatakan valid $(r$ hitung $>0.468)$ dan Reliabiltas (Cronbach alfa $>0,906$

\section{Analisa data}

Analisa Univariat menggunakan kuesioner dan Bivariat variable data tidak berdistribusi normal maka dipakai uji wilcoxon. Untuk melihat hubungan sesudah pelatihan digunakan uji spearmen rho.

HASIL PENELITIAN

Karakteristik responden

Tabel 1

Rerata Umur Dan Masa Kerja Manajer di RSI Ibnu Sina Pekanbaru Tahun $2013(n=35)$

\begin{tabular}{ccc}
\hline \multicolumn{1}{c}{ Variabel } & $\boldsymbol{F}$ & \% \\
\hline Umur & & \\
$\bullet \quad$ Muda & 12 & 34,3 \\
$\bullet \quad$ Tua & 23 & 65,7 \\
Lama kerja & & \\
$\bullet \quad$ Baru & 2 & 5,7 \\
$\bullet \quad$ Lama & 33 & 94,3 \\
Jenis kelamin & & \\
$\bullet \quad$ Laki-laki & 2 & 5,7 \\
$\bullet \quad$ Perempuan & 33 & 94,3 \\
\hline
\end{tabular}


Tabel 2

Distribusi Frekuensi Kemampuan Perawat Manejer Melakukan Evaluasi SOP Tindakan Keperawatan diRSI ibnu sina Pekanbaru sebelum dilakukan pelatihan $(\mathrm{n}=\mathbf{3 5})$

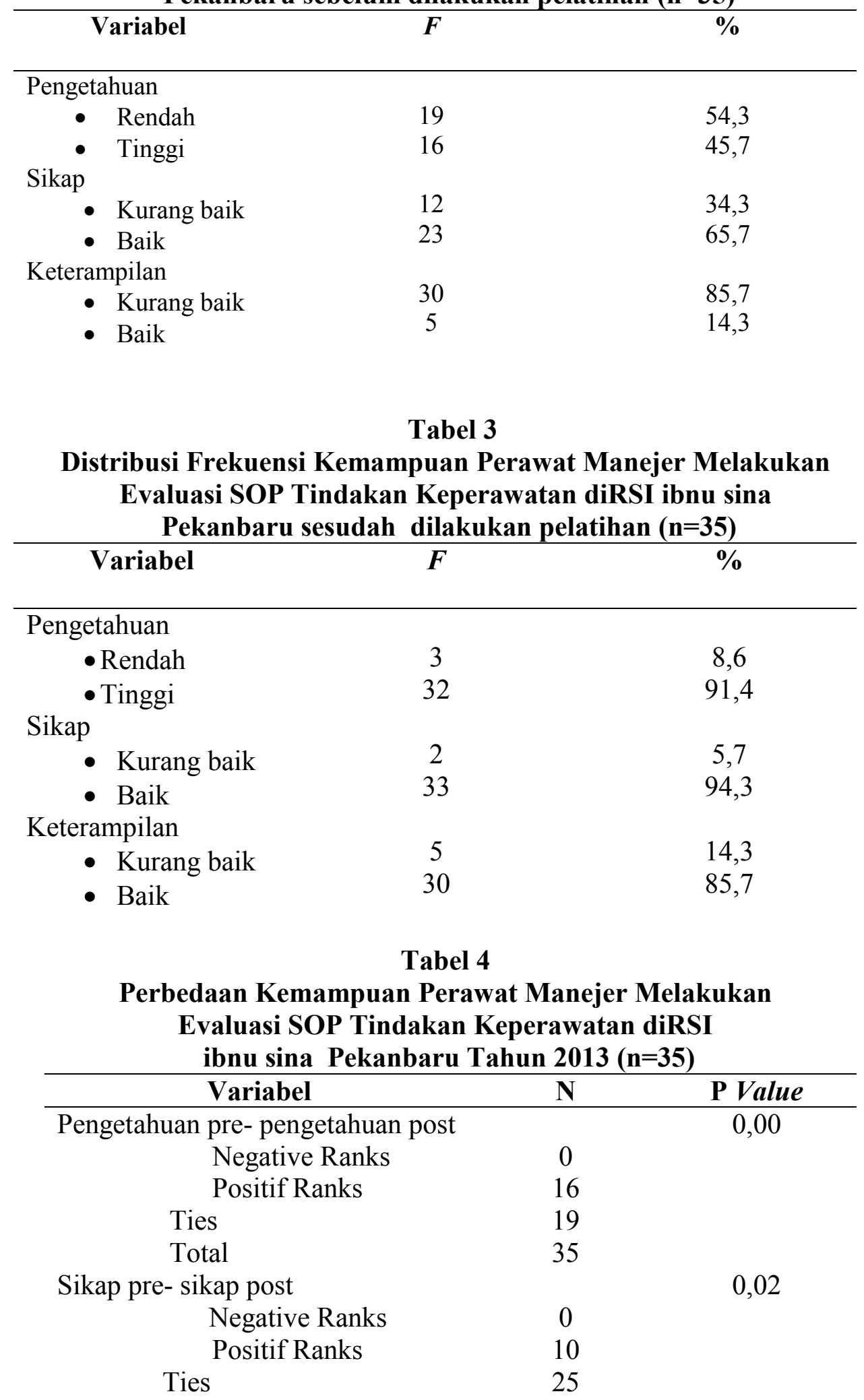


Total

Keterampilanpre-keterampilan post

Negative Ranks

Positif Ranks

Ties

Total
35

0,00

0

25

10

35

Tabel 5

Analisa Hubungan Karakteristik Dengan Kemampuan Meliputi

Pengetahuan, Sikap dan Keterampilan Dalam Melakukan Evaluasi

SOP Tindakan Keperawatan Setelah Mendapat Pelatihan

Di RSI Ibnu Sina Pekanbaru Tahun 2013 (n=35)

\begin{tabular}{|c|c|c|c|}
\hline Variabel & Pengetahuan & Sikap & Keterampilan \\
\hline Umur & & & \\
\hline $\mathrm{r}$ & $-0,221$ & $-0,178$ & $-0,295$ \\
\hline $\mathrm{p}$ & 0,202 & 0,307 & 0,85 \\
\hline
\end{tabular}

Masa kerja

$\mathrm{p}$

$-0,75$

$-0,61$

$-0,101$

0,667

0,729

0,566

Jenis Kelamin

$\mathrm{r}$

$-0,75$

$-0,61$

$-0,101$

$\mathrm{p}$

0,667

0,727

0,566

\section{PEMBAHASAN}

Diketahui bahwa umur responden lebih dari separoh $(65,7 \%)$ memiliki umur tua,dapat disimpulkan rata-rata usia responden memiliki umur yang tua. Menurut analis peneliti umur perawat manejer yang sangat bervariasi ini yaitu dengan usia termuda 27 tahun dan usia tertua 47 tahun tidak mempengaruhi semangat para manejer untuk tetap menambah pengetahuan terutama melalui pelatihan. Untuk lama bekerja perawat manejer umumnya $(94,3 \%)$ memiliki lama kerja yang relative lama. Menurut analisis peneliti bahwa masa kerja perawat manejer umumnya memiliki lama kerja yang cukup lama yaitu masa kerja terendah 4 tahun dan masa kerja tertinggi 20 tahun. Sedangkan untuk jenis kelamin perawat manejer umumnya $(94,3 \%)$ berjenis kelamin perempuan, secara teoritis tidak ada perbedaan produktivitas kerja antara perawat wanita dengan perawat lakilaki.

Kemampuan Tingkat Pengetahuan Sesudah Diberikan Pelatihan

Dari hasil penelitian semua responden setelah pelatihan umumnya $(91,4 \%)$ pengetahuan sudah tinggi. Hasil penelitian ini sejalan dengan penelitian Dianur Hikmawati (2012), terjadi dampak efektif yang diukur persepsi dan reaksi peserta pelatihan berupa peningkatan pengetahuan, sikap dan keterampilan. Perubahan prilaku ini terjadi ditempat kerja benar- benar 
dapat dimamfaatkan dan diaplikasikan didalam prilaku kerja sehari-hari dan berpengaruh secara signifikan terhadap kerja peserta pelatihan.

Menurut analisa peneliti pelatihan merupakan pendidikan tambahan bagi pegawai sebagai suatu proses untuk menghasilkan suatu

perubahan perilaku yang dapat berbentuk peningkatan kemampuan kognitif, afektif dan psikomotor, yang mampu bertahan dan akan terus diaplikasikan dalam dunia kerja apabila diberikan pelatihan dan pendidikan tambahan, maka perawat diharapkan. Semakin mampu menjalankan tugasnya. Sebaiknya pelatihan dan pengembangan karyawan dilakukan secara kontinyu dan dinamis.

Sikap Perawat Manejer Sesudah Diberikan Pelatihan

Berdasarkan hasil penelitian untuk sikap perawat manejer sesudah diberikan pelatihan umumnya $(94,3 \%)$ sudah memiliki sikap yang baik.

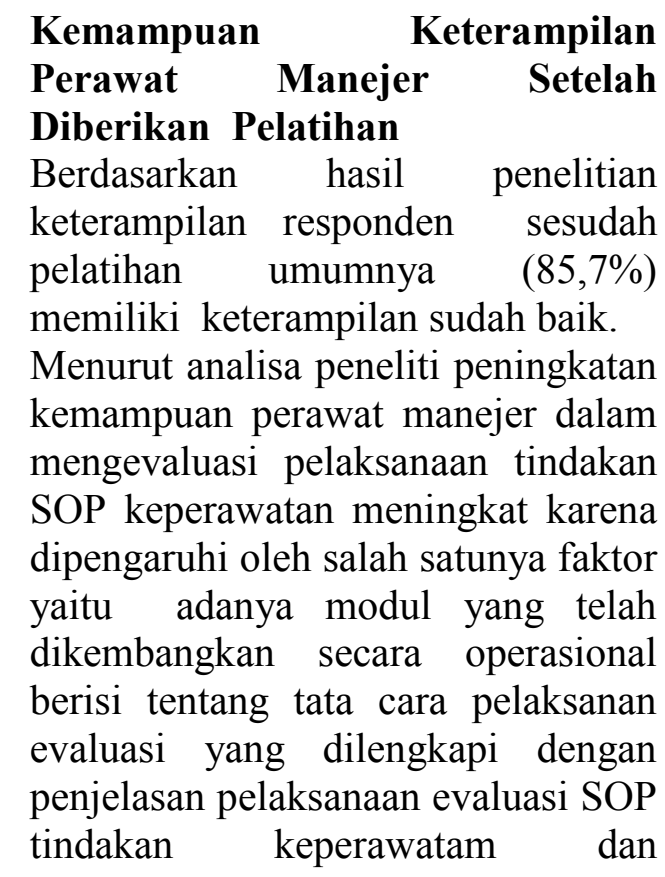

dilanjutkan dengan kegiatan pendampingan, sehingga perawat manejer dalam hal ini responden dapat langsung membaca modul maupun berdiskusi langsung pada saat kegiatan pendampingan dilakukan.

\section{KESIMPULAN DAN SARAN}

\section{Kesimpulan:}

1. Karakteristik perawat manejer di RSI Ibnu sina Pekanbaru berdasarkan umur separoh memiliki umur tua, dan lama bekerja umumnya memiliki lama kerja relatife lama, dan untuk jenis kelamin responden umumnya berjenis kelamin perempuan.

2. Pengetahuan manejer perawat sebelum pelatihan masih memiliki pengetahuan rendah.

3. Sikap manejer perawat sebelum pelatihan sebagian memiliki sikap baik.

4. Keterampilan manejer perawat sebelum pelatihan umumnya memiliki keterampilan kurang baik tentang evaluasi SOP tindakan keperawatan dengan menggunakan model evaluasi Brinkerhoff.

5. Terdapatnya perbedaan pengetahuan perawat manejer tentang evaluasi SOP tindakan keperawatan dengan menggunakan evaluasi model Brinkerhoff sebelum dan sesudah diberikan pelatihan.

6. Terdapatnya perbedaan sikap perawat manejer tentang evaluasi SOP tindakan keperawatan dengan menggunakan evaluasi model Brinkerhoff sebelum dan sesudah diberikan pelatihan.

7. Terdapatnya perbedaan keterampilan perawat manejer tentang evaluasi SOP tindakan 
keperawatan dengan menggunakan evaluasi model Brinkerhoff sebelum dan sesudah diberikan pelatihan.

8. Tidak terdapat hubungan antara karakteristik perawat manejer meliputi umur, jenis kelamin dan lama kerja dengan kemampuan evaluasi SOP tindakan keperawatan meliputi pengetahuan, sikap dan keterampilan.

\section{Saran}

Saran Untuk Pengembangan Pelayanan Keperawatan

1. Perlu dilakukan upaya menyelenggarakan pelatihan kepemimpinan secara berkesinambungan,

2. Pentingnya kebijakan organisasi berupa untuk menindaklanjuti pelaksaaan pengawasan dan evaluasi terhadap perawat pelaksanan apakah telah bekerja sesuai SOP.

3. Melakukan monev terhadap hasil pelatihan secara periodik melihat sejauh mana pengaruh pelatihan dalam lingkungan pekerjaan nyata.

4. Perlu dilakukannya revisi dan pembaharuan SOP tindakan keperawatan yang terbaru.

\section{DAFTAR PUSTAKA}

Agus, Kuntoro (2010), Kuesioner pengetahuan dan sikap dalam penelitian kesehatan Jakarta: Salemba Medika

Angela gillis \& Winston Jackson (2002), Reseach for nurses methods and interpretation, Davis Company Philadelphia

Arifin, Zainal (2011), Evaluasi pembelajaran edisi 3
Bandung : PT Remaja
Rosdakarya

Brinkerhoff, Robert O;

et.al.1983.Program

evaluation a practioner's guide for trainer and educators, Source book and case book.Boston

Dahlan, Sopiyudin (2011), Statistik Untuk Kedokteran dan Kesehatan.edisi 5 Salemba Medika

Farida (2008), Evaluasi program dan instrument evaluasi edisi 1 Jakarta: Rineka Cifta

Gillies (1994), Nursing Manjement : A system Approach, third ed, Saunder,Co, Philadelphia,AS.

H. Fayol, General and industrial manajemen, trans, by $C$, Storrs (London : Pitman \& Sons 1987)

Kozier,et all Fundamental of Nursing Concept, Proses and practice 4 th ed. Addison Wesey Publishing Company Inc.California, 1991.

Kirkpatrick,D.I (1998), Evaluating Training program: The four Level.San Fransisco: BerretKoehler Publisher,Inc

Lynn Basford (2006), Teori dan praktik keperawatan,Edisi 1, Jakarta, Buku kedokteran EGC

Mardapi, D (2000), Evaluasi Pendidikan dalam Konvensi Pendidikan Nasional, 
Universitas Negeri Jakarta, Jakarta 19-23 September

Marquis,BL \& Huston,C.J (2010). Leadership Role and Management Fungtions in Nursing,Theory and Apllications, ed/7.philadelphia:Wolter

Kluwer Lippincot Williams Wilkins

Muhamad Syaiful Hayat,( 2004), Pembelajaran berbasis Praktikum untuk mengembangkan sikap ilmiah siswa, Pasca Sarjana.UPI

Nursalam (2002), Manajemen Keperawatan Aplikasi dalam Praktik Keperawatan Profesional Edisi1, Jakarta Salemba Medika.

Notoatmodjo,S(2005), Metodologi penelitian kesehatan, Jakarta: PT Rineka cifta

Potter,PA \& Perry,AG (2005), Buku ajar fundamental keperawatan konsep proses, dan praktik, Edisi 4.Volume 2 , Alih bahasa: komasari Jakarta: EGC, Jakarta, 2005.

Rakhmat, Jalaluddin (1998),Metode penelitian komunikasi ,Bandung: Rosda Karya

Ratna, Sitorus (2002), Model Praktik keperawatan profesional di Rumah sakit: EGC.

Riyadi, sujono,dkk (2012), Standar operational Prosedur
(SOP) dalam praktik klinik keperawatan dasar, Yogyakarta: Pustaka pelajar

Robbins, S.P (2003), Organizational behaviour. Tenth edition.New Jersey : Pearson Education,Inc.

Sastroasmoro dan Sofyan ismael (2008), Dasar-dasar metodologi penelitian Klinis.Jakarta: Universitas Indonesia

Suyanto,(2008), Kepemimpinan dan manajemen keperawatan, Edisi kedua, Jogjakarta: Mitra cendikia press

Swanburg (2000), Pengantar
kepemimpinan
manajemen
keperawatan,Edisi1,
Jakarta: Buku kedokteran
EGC.

